\title{
EI Desarrollo Humano Integral en la teología cristiana
}

\section{Carlos García de Andoin'}

Resumen: El autor realiza un recorrido a lo largo de la teología cristiana de los últimos cincuenta años sobre el concepto y modelo de desarrollo humano integral. La lglesia que sale del concilio es especialmente consciente de que su misión sacramental en el mundo. $Y$ no es posible el anuncio de la buena noticia al margen del compromiso por la mejora de las condiciones materiales y sociales de vida de los pueblos. la lglesia va a plantear un "hecho moral", el subdesarrollo no es responsabilidad de los indigentes, ni una fatalidad social o natural, sino un hecho que apela a la responsabilidad moral de todos, especialmente de los ciudadanos y de la política de los países desarrollados El desarrollo no es posible sin redistribución de la riqueza, pero el desarrollo no se reduce al simple crecimiento económico. Para ser auténtico debe ser integral, es decir, promover a todos los hombres y a todo el hombre.

Palabras Clave: Populorum Progressio, desarrollo humano integral, subdesarrollo, Caritas in veritate.

Fecha de recepción: 28-30 de junio de $2017^{2}$.

Fecha de admisión definitiva: 21 de junio de 2018.

' Director, Instituto Diocesano de Teología y Pastoral de Bilbao.

${ }^{2}$ Fecha de celebración del Simposio. 


\section{Integral Human Development in Christian theology}

Abstract: The author carries out a review, all along the Christian theology of the last fifty years, on the concept and model of integral human development. The Church coming out of the Council is especially conscious that its mission in the world is sacramental. And communication of the Good News is not possible outside the commitment to the betterment of the material and social conditions of the peoples. The Church is going to propose a "moral fact," the underdevelopment is not the responsibility of the poor folks, nor a social or natural fatality, but a fact that appeals to the responsibility of all, especially of the citizens and of the politics of the developed countries. The development is not possible without a redistribution of the wealth, but development is not confined to the simple economic growth. For it to be authentic, it must be integral, that is to say, it must promote all men and the whole man.

Key words: Populorum Progressio, integral human development, underdevelopment, Caritas in veritate.

\section{Le Développement Humain Intégral dans la Théologie Chrétienne}

Résumé: L'auteur réalise un parcours le long de la théologie chrétienne des dernières cinquante années sur le concept et le modèle de développement humain intégral. L'Église issue du concile est particulièrement consciente de sa mission sacramentelle dans le monde. Et l'annonce de la Bonne Nouvelle n'est pas possible sans l'engagement pour l'amélioration des conditions matérielles et sociales de la vie des peuples. L'Église pose un «fait moral»: le sous-développementn'est pas la responsabilité des indigents, ni une fatalité sociale ou naturelle, mais un fait qui fait appel à la responsabilité morale de tous, spécialement des citoyens et de la politique des pays développés. Le développement $\mathrm{n}^{\prime}$ est pas possible sans la redistribution de la richesse, quoique le développement ne doit pas être réduit à la seule croissance économique. Pour que le développement soit réel il doit être intégral, c'est-à-dire, promouvoir tous les êtres humains et l'intégralité de l'être humain.

Mots clé: Populorum Progressio, développement humain intégral, Sous-développement, Caritas in veritate.

Título pretencioso este que la organización nos ha propuesto: "el Desarrollo Humano Integral en la teología cristiana". Sólo el Catecismo sería capaz de responder a la cuestión en media hora con éxito y precisión. Así que he acotado el tema para referirme a la teología cristiana de los textos pontificios de la doctrina social de la Iglesia.

Fue, en efecto, Pablo VI quien en la Encíclica Populorum Progressio (1967) propone el "desarrollo integral". Es la respuesta de una Iglesia recién salida del Vaticano Il ante la nueva conciencia sobre la miseria y el subdesarrollo en que viven miles de millones de personas. Debe reconocerse a cada pueblo igual "derecho a sentarse en la mesa del banquete común" (Lc. 16,21). La Iglesia ya no podía seguir 
pensando el mundo de manera eurocéntrica: "la cuestión social ha tomado una dimensión mundial" (PP 3).

\section{Desarrollo}

El término desarrollo procede del campo semántico de las ciencias económicas y sociales. El desarrollo económico servía para clasificar los países: países desarrollados, en subdesarrollo o en vías de desarrollo. Podía haberse buscado un término más interior a la tradición de la Iglesia. Sin embargo, no se hizo: Pablo $\mathrm{VI}$ eligió desarrollo, un término del acervo común secular.

La Iglesia que sale del concilio es especialmente consciente de que su misión sacramental en el mundo (LG 1) no puede hacerse al margen de los gozos y esperanzas, de las tristezas y las angustias concretas que viven las personas (GS 1). Sabe que su misión salvífica tiene una dimensión material y económica ineludibles. No es posible el anuncio de la buena noticia al margen del compromiso por la mejora de las condiciones materiales y sociales de vida de los pueblos. No es posible sin redistribución de la riqueza.

Si a fines del XIX la cuestión social era la condición obrera (Rerum Novarum), a mediados del XX el eje de la cuestión social es el subdesarrollo, el abismo de la desigualdad entre los pueblos (Populorum Progressio). En ambos casos, la Iglesia va a plantear un "hecho moral" (SRS 9). El subdesarrollo no es responsabilidad de los indigentes, ni una fatalidad social o natural, sino un hecho que apela a la responsabilidad moral de todos, especialmente de los ciudadanos y de la política de los países desarrollados: "los pueblos hambrientos interpelan hoy, con acento dramático, a los pueblos opulentos" (PP 3).

\section{Desarrollo humano integral}

Ahora bien, el desarrollo propuesto por la Iglesia, que debía ser socio-económico, no podía ser sólo económico, material. Pablo Vl escribe así cuál es la visión cristiana del desarrollo: "el desarrollo no se reduce al simple crecimiento económico. Para ser auténtico debe ser integral, es decir, promover a todos los hombres y a todo el hombre" (PP 14). Debe alcanzar a todos los pueblos, a la humanidad entera y a todas las dimensiones de la experiencia humana donde se decide la 
dignidad humana: las condiciones materiales, la salud y la educación, la libertad moral y política, el crecimiento personal y comunitario y el desarrollo espiritual. Era necesaria una nueva acción "que tenga como punto de partida una clara visión de todos los aspectos económicos, sociales, culturales y espirituales" (PP 13). Para la Populorum Progressio "que los pueblos salieran del hambre, la miseria, las enfermedades endémicas y el analfabetismo" implicaba: a) económicamente, "su participación activa y en condiciones de igualdad en el proceso económico internacional"; b) socialmente, "su evolución hacia sociedades solidarias y con buen nivel de formación"; c) políticamente, "la consolidación de regímenes democráticos capaces de asegurar libertad y paz" (CiV 21). Es una visión articulada y complexiva del desarrollo.

Pero, además, el término integral, en pluma de Pablo Vl, no puede entenderse sin referirnos al intelectual francés Maritain y a los debates del humanismo de la época. De un lado, frente al humanismo burgués y materialista, que pone la felicidad en la búsqueda exclusiva del poseer, donde prevalece el tener frente al ser: "el tener más, lo mismo para los pueblos que para las personas, no es el fin último" (PP 19).

De otro, ante el humanismo ateo, que sólo puede concebir la plenitud humana negando a Dios. Así cuando Pablo VI quiere explicar a modo de síntesis "¿qué quiere decir el desarrollo integral de todo hombre y de todos los hombres?" Dice: "es un humanismo pleno el que hay que promover" citando el Humanismo integral (1936) (PP 41). Maritain, ante el humanismo sin Dios, o contra Dios, postulaba un pensamiento profundamente humanista, pero el suyo era un "humanismo teocéntrico, enraizado allá donde el hombre tiene sus raíces; humanismo integral, humanismo de la Encarnación" (Maritain, 1999: 104). Pablo VI cita también El drama del humanismo ateo de $\mathrm{H}$. De Lubac (1945). El humanismo integral se opone al humanismo cerrado, impenetrable a los valores del espíritu y a Dios.

Ciertamente el hombre puede organizar la tierra sin Dios, pero, al fin y al cabo, sin Dios no puede menos de organizarla contra el hombre. El humanismo exclusivo es un humanismo inhumano (PP 42).

Por cierto, es de notar que en la Laudato $\mathrm{Si}^{\prime}$, el papa Francisco ha recurrido también al adjetivo integral para ofrecer la visión cristiana de la ecología, "ecología integral" (LS 62 y cap. IV). Así, con ello, destaca varios aspectos. Primero, la relación de la crisis medio-ambiental con el modelo de desarrollo, producción y consumo, con la estructura socio-económica (LS 138) frente a la interpretación medio-ambientalista; segundo, una ecología que integra el planteo social y el planteo ecológico (LS 49) frente al "biocentrismo" de la deep ecology, que disuelve la singularidad del ser humano; tercero, una ecología personal, no solo estructural, que concierne 
a la vida cotidiana de las personas; cuarto, una defensa del ecosistema cultural del ser humano y su biodiversidad, no sólo natural sino cultural; y, por último y subrayadamente, la conexión cristiana de la ecología con la dimensión espiritual y trascendente del ser humano.

Sin duda, el desarrollo humano integral fue un gran hallazgo de Pablo VI. Tres décadas después es retomado por Juan Pablo II en Solicitudo Rei Socialis y cuatro décadas después por Benedicto XVI en Caritas in Veritate. Dice Benedicto XVI, "Pablo VI indicó en el desarrollo, humana y cristianamente entendido, el corazón del mensaje social cristiano" (CiV 13). Ambos hacen propio el ideal del desarrollo humano integral, enriqueciendo su significado.

De hecho "promover un humanismo integral -y solidario-3" -veremos al final que también sostenible-, ha llegado a constituir el horizonte de la reflexión, del juicio y de la acción de la doctrina social de la Iglesia (Compendio de la doctrina social de la Iglesia, n. 6). En consecuencia, precisamente hace un año fue creado el dicasterio para el Desarrollo Humano Integral, lo que convierte este horizonte en la prioridad de la acción social y política de la Iglesia.

\section{El desarrollo: vocación de Dios para el ser humano}

En Sollicitudo Rei Socialis, hace 30 años, con ocasión del 20 aniversario de Populorum Progressio, Juan Pablo II, poco antes de la caída del muro, se preguntaba si el capitalismo liberal y el colectivismo marxista

eran susceptibles de transformaciones y capaces de ponerse al día, de modo que favorezcan o promuevan un desarrollo verdadero e integral del hombre y de los pueblos en la sociedad actual (SRS 21).

Era un contexto de crítica a los dos bloques, a su antagonismo geopolítico y a la carrera armamentística.

Desde la perspectiva teológica nos interesan tres puntos de esta encíclica. En primer lugar, el fundamento teológico del imperativo del desarrollo humano. Se habla de "desarrollo pleno, más humano, a la altura de la auténtica vocación del hombre y

${ }^{3}$ La segunda parte de la Encíclica se titula precisamente "Hacia el desarrollo solidario de la humanidad" (nn. 43 y ss.). "El desarrollo integral del hombre no puede darse sin el desarrollo solidario de la humanidad" (PP 43). 
de la mujer" (SRS 28). En segundo lugar, la crítica teológica al progreso. En tercer lugar, la propuesta, del concepto "estructuras de pecado" para diagnosticar con más precisión "la raíz de los males que nos aquejan" (SRS 36).

Veamos una por una.

Primera. El desarrollo humano integral es realización de la vocación de Dios para con el hombre. Ya lo había planteado Pablo VI. Éste lo menciona como la "vocación al crecimiento". Según la teología cristiana de la creación, "en los designios de Dios, cada hombre está llamado a desarrollarse, porque toda vida es una vocación" (PP 15) a "crecer en humanidad, valer más, ser más" a los ojos de Dios. Del mismo modo que la creación entera está ordenada a su Creador, la creatura también está orientada hacia Dios. En perspectiva neotestamentaria, la "inserción en el Cristo vivo" da forma a esta vocación de crecimiento, de plenitud y de desarrollo personal. El desarrollo humano es así un imperativo que viene de Dios, "un resumen de nuestros deberes". No es facultativo (PP 16).

Juan Pablo II arrancando de esta visión insiste en que la noción de desarrollo "no es solamente laica o profana", sino "la expresión moderna de una dimensión esencial de la vocación del hombre" (SRS 30). El ser humano está determinado como creatura e imagen de Dios a cooperar con Él en la tarea del desarrollo y perfeccionamiento de la Creación. Pero tal facultad no le permite un dominio arbitrario sobre la realidad creada, sino que también le obliga "en el respeto a la imagen recibida". De este modo renunciar a la tarea de elevar la suerte de todo el hombre y de todos los hombres sería "faltar a la voluntad de Dios Creador". Alude a la parábola de los talentos y la dureza del juicio de Dios para con quien entierra y no cultiva el talento recibido (Mt. 25, 26-28). En SRS, la fe neotestamentaria en Cristo Redentor ilumina la naturaleza del desarrollo y orienta su realización. Cristo es "el primogénito de toda la creación"; "todo fue creado por él y para él" (Col. 1, 15-16) en él reside la plenitud (Col. 1,19). Cristo es la forma definitiva del desarrollo humano integral.

De acuerdo con esta concepción esta encíclica vincula de forma intrínseca el desarrollo auténtico al respeto de los derechos humanos. El verdadero desarrollo implica "una viva conciencia del valor de los derechos de todos y de cada uno" (SRS 33). No es conforme a la dignidad del hombre un tipo de desarrollo que no respete y promueva "los derechos humanos, personales y sociales, económicos y políticos, incluidos los derechos de las Naciones y de los pueblos" (SRS 33).

Segunda. En esta encíclica se acaba por elegir el término desarrollo, frente al del progreso, de la Populorum, al que se considera con connotaciones filosóficas 
iluministas (SRS 27). Intenta evitar la idea positivista o mecanicista del desarrollo como un "proceso rectilíneo, casi automático y de por sí ilimitado, como si el género humano marchara seguro hacia una especie de perfección indefinida". Desde una lectura cristiana de la historia, el desarrollo es "un momento de la historia iniciada en la creación", pero el progreso no puede ser considerado como una ley inexorable. Tiene una condición de posibilidad, la voluntad de Dios de hacer al hombre partícipe de su gloria por el acto de la creación. Tiene una historia que enseña que "no es un progreso necesario hacia lo mejor, sino más bien un acontecimiento de libertad, más aún, un combate de libertades" (SRS 27, en nota). Y tiene un fin, pero no necesario, sino vinculado a la promesa del rescate de la historia por Cristo (SRS 31).

En la opción terminológica, además, está una la crítica acusada a la visión "economicista" del desarrollo propia de la civilización consumista. Es inaceptable la miseria del subdesarrollo, pero también el super-desarrollo, que hace a las personas esclavas de la idolatría de la posesión y del consumo (SRS 28).

Tercera. El avance del desarrollo humano topa con una maraña de obstáculos extremos para hacerse paso. Donde Pablo VI hablaba de "estructuras opresoras" que "provienen del abuso del tener o del abuso del poder, de la explotación de los trabajadores o de la injusticia de las transacciones" (PP 21), Juan Pablo II, precisamente en este contexto de problemática del desarrollo humano, se ve en la necesidad de hablar de "estructuras de pecado" en un capítulo que la encíclica denomina "lectura teológica de los problemas modernos".

Frente al desarrollo se oponen intereses económicos, motivaciones políticas y egoísmos morales. Pero no basta la concepción tradicional del pecado. No sólo los individuos, sino también las naciones o los bloques tienen responsabilidad moral. Personas e instituciones acumulan un conjunto de factores negativos contrarios al bien común universal. Bajo determinadas decisiones "se ocultan verdaderas formas de idolatría: dinero, ideología, clase social y tecnología". Es preciso, por todo ello, hablar de "estructuras de pecado", para mostrar "cuál es la naturaleza real del mal al que nos enfrentamos en la cuestión del desarrollo de los pueblos". Diagnosticar el mal así, como estructura, permite identificar más adecuadamente la conversión necesaria para superarlo. ¿En qué dirección? Es necesaria una acción sistémica, de solidaridad entre los pueblos, entendida esta no como sentimiento superficial sino como la "determinación firme y perseverante de empeñarse por el bien común" (SRS 37 y 40) de inspiración evangélica. 


\section{Caridad en la Verdad, fundamento del desarrollo humano integral}

La encíclica social de Benedicto XVI Caritas in Veritate es toda ella un ejercicio intencional y expreso por actualizar la doctrina del Desarrollo Humano Integral. A la caída del muro de Berlín le ha sucedido la globalización. "Ha sido el motor principal para que regiones enteras superaran el subdesarrollo y es, de por sí, una gran oportunidad" en particular para los llamados países emergentes (CiV 33). Ha sido notable en estas décadas la mejora de los indicadores de Desarrollo Humano, el aumento de la riqueza mundial, habiendo disminuido la pobreza absoluta y la pobreza relativa. Pero el $30 \%$ de la población mundial ( 1.600 millones) sigue siendo pobre según el Índice de Pobreza Multidimensional y las desigualdades no se han minorado, sino que, tras la Gran Recesión, se agrava en los países emergentes y en el interior de los países ricos según el coeficiente Gini.

Benedicto XVI considera la Populorum Progressio un hito de referencia obligada en el magisterio social de la Iglesia, dice de ella que es «la Rerum novarum de la época contemporánea» (CiV 8). Reafirma que el "desarrollo humano integral es ante todo vocación" (CiV 11), pero de forma previa, introduce todo un capítulo para radicar teológicamente el mensaje sobre el desarrollo humano integral de la Populorum Progressio, frente a posibles interpretaciones secularistas del mensaje social de la Iglesia en un contexto de relativismo, su gran y quizá clarividente preocupación, desde los tiempos que fuera Prefecto de la Congregación para la Doctrina de la Fe. Dice así:

el punto de vista correcto, por tanto, es el de la Tradición de la fe apostólica, patrimonio antiguo y nuevo, fuera del cual la Populorum progressio sería un documento sin raíces y las cuestiones sobre el desarrollo se reducirían únicamente a datos sociológicos (CiV 10).

(No lo creo así, que el drama humano, quede en dato sociológico, por la ausencia de fe, aunque entiendo lo que quiere enfatizar).

Dos elementos destacan como diferenciales desde un punto de vista teológico.

En primer lugar. Propone la caridad, don de Dios y "vía maestra de la doctrina social de la Iglesia", como fundamento del auténtico desarrollo humano.

La verdad originaria del amor de Dios, que se nos ha dado gratuitamente, es lo que abre nuestra vida al don y hace posible esperar en un "desarrollo de todo el hombre y de todos los hombres», en el tránsito "de condiciones menos humanas a condiciones más humanas» (CiV 8). 
En Benedicto XVI el "verdadero desarrollo humano integral" (CiV 4) adquiere su fundamento en la caridad en la verdad. "Sólo con la caridad, iluminada por la luz de la razón y de la fe, es posible conseguir objetivos" del "auténtico desarrollo" (CiV 9). Estima que la razón "por sí sola, es capaz de aceptar la igualdad entre los hombres y de establecer una convivencia cívica entre ellos, pero no consigue fundar la hermandad". La fraternidad universal, contenido y fundamento del desarrollo humano integral, sólo nace en el contexto de una vocación o de un humanismo trascendente (CiV 19).

En segundo lugar, la reivindicación de la verdad, esto es, de la antropología cristiana revelada en Jesucristo, como garantía de un verdadero desarrollo humano. "El desarrollo humano integral como vocación exige también que se respete la verdad" (CiV 18). Benedicto XVI es consciente del relativismo creciente por el que divergen en múltiples direcciones las ideas sobre lo que es el ser humano y su desarrollo. "La fidelidad al hombre exige la fidelidad a la verdad, que es la única garantía de libertad (cf. Jn 8,32) y de la posibilidad de un desarrollo humano integral" (CiV 9) 4

¿Qué aportan estas dos perspectivas Caritas in Veritate que son una?

Básicamente introducen un principio hermenéutico, estrictamente teologal, a la propuesta de desarrollo humano integral. Intenta reconstruir en un época postmoderna y líquida las bases de un pensamiento nuevo y de una ética que, a diferencia de las seculares, está pensada y vivida "como si Dios existiese". Se trata de reproponer nuevamente un humanismo integral, estructuralmente abierto a la fraternidad y a la trascendencia en un contexto secular, plural y posmoderno (Toso, 2016:18).

\section{El desarrollo humano, sostenible e integral (LS I8)}

El pasado abril (4.4.17) el papa Francisco se preguntó con ocasión del 50 aniversario de la Populorum Progressio qué quiere decir hoy "¿la expresión 'desarrollo integral', es decir, el desarrollo de cada hombre y de todo hombre?". Respondió

\footnotetext{
${ }^{4}$ En este sentido se muestra crítico sobre las posibilidades de las estructuras políticas y sistemas sociales que no se basen en la libertad de las personas. "La vocación es una llamada que requiere una respuesta libre y responsable. El desarrollo humano integral supone la libertad responsable de la persona y los pueblos: ninguna estructura puede garantizar dicho desarrollo desde fuera y por encima de la responsabilidad humana" (CiV 17).
} 
señalando cuatro directrices de acción para el dicasterio recién creado 5 y puso de ejemplo a Jesucristo como ejemplo de la acción de la Iglesia en el ámbito del desarrollo integral: "la manifestación de Dios en Cristo [...] indica el camino y la modalidad del servicio que la Iglesia quiere ofrecer al mundo". Bajo esa luz "se puede entender lo que significa un desarrollo integral que no perjudica ni a Dios ni al hombre, porque asume toda la consistencia de ambos".

Esta es una característica de la fundamentación del desarrollo en Francisco. Su aproximación primeramente cristológica, inspirada en el Evangelio. "Cuanto hicisteis a uso de estos hermanos míos más pequeños a mí me lo hicisteis" (Mt 25,40). Los pobres son prolongación de la encarnación de Cristo y ahí reside el imperativo del compromiso con el desarrollo integral. "De nuestra fe en Cristo hecho pobre (2 Co 8,9) y siempre cercano a los pobres y excluidos brota la preocupación por el desarrollo integral de los más abandonados de la sociedad" (EG 186).

En este sentido Francisco supera por radicalización, el carácter segundo del compromiso social o de la doctrina social para la identidad cristiana. La propuesta del Evangelio "no es sólo la de una relación personal con Dios" (EG 180). El compromiso por el desarrollo humano integral pertenece al propio kerigma. "El kerygma tiene un contenido ineludiblemente social" (EG 177) ;

${ }^{5}$ 1) "Integrar a los diversos pueblos de la tierra. El deber de solidaridad nos obliga a buscar la modalidad justa de cooperación, para que no se produzca esa dramática desigualdad entre el que tiene mucho y el que no tiene nada, entre el que descarta y el descartado". 2) En segundo lugar, "se trata de ofrecer modelos practicables de integración social. Todos tenemos una contribución que ofrecer al conjunto de la sociedad. Todos tenemos una peculiaridad que puede ser de ayuda para facilitar el que podamos vivir juntos. Nadie está excluido de aportar algo al bien común. Esto es, al mismo tiempo, un derecho y un deber". 3) "Integrar en el desarrollo todos aquellos elementos que lo hacen realidad". Los diferentes elementos que articulan la sociedad, la economía, las finanzas, el trabajo, la cultura, la vida familiar, la religión, son, cada uno de ellos en su especificidad, "un elemento irrenunciable de ese crecimiento. Ninguno de ellos puede absolutizarse ni tampoco excluirse". 4) Se trata también "de integrar la dimensión individual y la comunitaria" frente al individualismo autorreferencial y a la masificación que nos debilita frente a los grandes poderes globales. 5) Por último se trata de integrar entre ellos cuerpo y alma. "el desarrollo no consiste en el tener a disposición cada vez más bienes, para un bienestar solamente material. Integrar cuerpo y alma significa además que ninguna obra de desarrollo podrá llegar verdaderamente a su fin si no respeta ese lugar en el cual Dios está presente para nosotros y habla a nuestro corazón" Cfr. https://w2.vatican.va/content/francesco/es/ speeches/2017/april/documents/papa-francesco_20170404_convegno-populorum-progressio.html

${ }^{6}$ Confesar a un Padre que ama infinitamente a cada ser humano implica descubrir que "con ello le confiere una dignidad infinita» [141]. Confesar que el Hijo de Dios asumió nuestra carne humana significa que cada persona humana ha sido elevada al corazón mismo de Dios. Confesar que Jesús dio su sangre por nosotros nos impide conservar alguna duda acerca del amor sin límites que ennoblece a todo ser humano. Su redención tiene un sentido social porque «Dios, en Cristo, no redime solamente 
"todo el camino de nuestra redención está signado por los pobres" (EG 197)

Pero además introduce una asimetría fundada en el mismo Dios sobre el universalismo del compromiso por el desarrollo humano integral.

Dios les otorga "su primera misericordia» lo que lleva a la opción de la Iglesia por los pobres entendida como una "forma especial de primacía en el ejercicio de la caridad cristiana, de la cual da testimonio toda la tradición de la Iglesia» (EG 198).

Desde la perspectiva de la teología de la creación, Francisco destaca el principio del destino universal de los bienes, la prioridad del Bien Común y consecuentemente la centralidad de la redistribución del ingreso.

Mientras no se resuelvan radicalmente los problemas de los pobres, renunciando a la autonomía absoluta de los mercados y de la especulación financiera y atacando las causas estructurales de la inequidad, no se resolverán los problemas del mundo y en definitiva ningún problema. La inequidad es raíz de los males sociales (EG 202).

Insiste en la insuficiencia del mercado y de las políticas neoliberales del derrame para garantizar esta redistribución, el desarrollo humano integral y la inclusión social (LS 109).

Finalmente, la aportación sustantiva de Francisco al desarrollo humano integral de Populorum Progressio es la cualidad de que ha de ser un desarrollo sostenible. Y ello resulta de una lectura teológica de la crisis ecológica.

No es el primer texto pontificio que vincula crisis ecológica y desarrollo humano ${ }^{8}$.

la persona individual, sino también las relaciones sociales entre los hombres》 [142]. Confesar que el Espíritu Santo actúa en todos implica reconocer que Él procura penetrar toda situación humana y todos los vínculos sociales: "El Espíritu Santo posee una inventiva infinita, propia de una mente divina, que provee a desatar los nudos de los sucesos humanos, incluso los más complejos e impenetrables» [143]. (EG 178).

7 Es una dimensión inexcusable de la evangelización.

La nueva evangelización es una invitación a reconocer la fuerza salvífica de sus vidas y a ponerlos en el centro del camino de la lglesia. Estamos llamados a descubrir a Cristo en ellos, a prestarles nuestra voz en sus causas, pero también a ser sus amigos, a escucharlos, a interpretarlos y a recoger la misteriosa sabiduría que Dios quiere comunicarnos a través de ellos (EG 198).

${ }^{8}$ Sollicitudo Rei Socialis incluye ya la dimensión medioambiental, la conciencia sobre los límites éticos y biológicos de la relación del ser humano con la naturaleza (SRS 34). Centesimus Annus plantea abiertamente la cuestión ecológica (CA 37); también Caritas in Veritate (n. 51). 
Sin embargo, una encíclica Laudato $\mathrm{Si}^{\prime}$, dedicada íntegramente a la misma otorga una centralidad a la cuestión que es realmente novedosa.

Leer Populorum Progressio desde Laudato Si', cinco décadas después conlleva inevitablemente la pregunta de si no queda escaso el "principio de discernimiento" que Pablo VI proponía para identificar el verdadero desarrollo: "todos los hombres y todo el hombre» (EG 81). Hoy el verdadero desarrollo debe incluir también "el cuidado de la casa común", la totalidad de lo creado, y sin duda, el desarrollo o es sostenible o no es humano, porque lo es a costa de las futuras generaciones; ni integral, porque quiebra la comunión del ser humano con la naturaleza, con la creación de Dios. Así que "Desarrollo humano, sostenible e integral" (LS 18).

El peligro de autodestrucción del ecosistema planetario, los límites del crecimiento, que no es universalizable, la especial vulnerabilidad de los países pobres ante los impactos de un cambio climático del que somos especialmente responsables los países ricos -la deuda ecológica- nos deben llevar a un replanteamiento de la relación con la casa común. Con acierto se propone en Laudato Si': "No habrá una nueva relación con la naturaleza sin un nuevo ser humano". O lo que es lo mismo "no hay ecología sin una adecuada antropología" (LS 118). Esta es una perspectiva realmente novedosa para Populorum Progressio, que probablemente también peca del antropocentrismo moderno.

Laudato Si' identifica una "estructura de pecado": el paradigma tecnocrático, raíz humana de la crisis ecológica (cap. $3^{\circ}$ ). "En él se destaca un concepto del sujeto que progresivamente, en el proceso lógico-racional, abarca y así posee el objeto que se halla afuera. Ese sujeto se despliega en el establecimiento del método científico con su experimentación, que ya es explícitamente técnica de posesión, dominio y transformación. Es como si el sujeto se hallara frente a lo informe totalmente disponible para su manipulación" (LS 111). Señala asimismo la necesidad de la "conversión ecológica" (LS 216 y ss): no bastan respuestas urgentes y parciales a los problemas medioambientales; es necesaria "una mirada distinta, un pensamiento, una política, un programa educativo, un estilo de vida y una espiritualidad que conformen una resistencia ante el avance del paradigma tecnocrático". La humanidad debe replantearse su relación con la naturaleza del "dominio" de Gn 1 al "cuidado" de Gn 2.

El desafío urgente de proteger nuestra casa común incluye la preocupación de unir a toda la familia humana en la búsqueda de un desarrollo sostenible e integral, pues sabemos que las cosas pueden cambiar. El Creador no nos abandona, nunca hizo marcha atrás en su proyecto de amor, no se arrepiente de habernos creado. La humanidad aún posee la capacidad de colaborar para construir nuestra casa común (LS 13). 


\section{Conclusión. Tres cuestiones}

El cardenal Turkson decía el pasado abril que el Los Objetivos de Desarrollo Sostenible a partir de 2015 incluyen parámetros distintos que los relacionados con el PIB y se presentan como un camino hacia la dignidad, pero se debe prestar más atención a la dimensión trascendental del desarrollo. "Sin Dios, el desarrollo se trunca". Asimismo manifestaba que "la noción del Desarrollo Humano Integral necesita una mayor elaboración en teología, doctrina social y antropología cristiana"9.

Tras este ejercicio de actualización intertextual sobre el DHI, desde una perspectiva teológica, merece ser subrayado que de la mano de la lectura de los signos de los tiempos, en este caso del llamado en un tiempo "subdesarrollo", ha habido un proceso de elaboración teológica que ha llevado a una teología pensada desde las estructuras de pecado en el mundo. $\dot{2}^{N}$ o cabría plantearse asimismo la cuestión de las "estructuras de la gracia", mediaciones estructurales a través de las cuales se encarna el misterio de la salvación, más allá de la propia Palabra de Dios o de la propia Iglesia, precisamente en clave de la lógica del don que propone CiV.

En segundo lugar. La Doctrina Social de la Iglesia ha dado por supuesto que "no tiene soluciones técnicas que ofrecer" al desafío del desarrollo (PP 13 y SRS 41). Sin embargo, la acción de los cristianos en múltiples ámbitos ha generado, desde la subjetividad de la sociedad, pero también desde la acción del Estado, múltiples respuestas. Es cierto que la verdad de una solución técnica no debe ser establecida en ningún caso por el magisterio pontificio. Pero ello siembre que se piense de una maera deductiva. Estimo que la inspiración y la originalidad cristiana generan prácticas concretas, buenas prácticas, que otro tipo de teología de compañía, memoria y profecía (Forte).

Finalmente, la reflexión teologica cristiana sobre el DHSI esta falta de un desarrollo más trinitario. Como hemos visto es una teología hecha de Dios Padre, autor de la Creación que llama al ser humano a la colaboración en el desarrollo humano; de Cristo, Verbo encarnado, Humanidad Nueva que es criterio de discernimineto del DH Integral. Sin embargo, queda difuminado el papel del Espíritu, señor y dador de vida, "Espíritu allende el Verbo" (Von Balthasar). La profudización en la Ecología integral, desde el punto de vista de la teología cristiana, nos debe llevar a una consideración del DHI desde la inhabitación del Espíritu de Dios en la totalidad de lo creado -ser humano, seres vivos, planeta y universo- y de el DHI en el dinamimo histórico y escatológico de la comunión trinitaria, hasta "ser Dios todo en todo" (1 Cor. 15, 27).

${ }^{9} \mathrm{hHtp}: / / \mathrm{www}$.juspax-es.org/news/promoviendo-el-desarrollo-humano-integral/ 